\title{
Why do higher education students drop out? Evidence from Spain
}

\author{
Gérard LASSIBILLE
}

Institut de Recherche sur 1'Economie de l'Education, Centre National de la Recherche Scientifique, Université de Bourgogne, France

\section{Lucía NAVARRO GóMEZ}

Facultad de Ciencias Económicas y Empresariales, Departamento de Estadística y Econometría, El Ejido, Málaga, Spain

Article publié dans Education Economics, Vol. 16, No. 1, March 2008, pp.89-105

DOI: $10.1080 / 09645290701523267$

http://dx.doi.org/10.1080/09645290701523267

\section{Abstract:}

This paper seeks to advance our understanding of the drop-out behavior of students in higher education. Our results are based on longitudinal data for 7000 students who embarked on short and long programs from one university in Spain and who were observed over an eight-year period ending in 2004. The statistical analysis is carried out in a competing-risks framework. We find that academic preparedness is one of the major influences on student completion. Additionally, older students and students who delay entry into higher education are more likely to drop out before graduating. Our analysis provides guidance about the role that financial support plays in reducing drop-out rates; we also find that family characteristics are significant factors in explaining student drop out in long programs.

\section{Introduction}

Dropping out has severe consequences for the individuals involved as well as for the society that finances most of the cost of service delivery. Having a better understanding of which students are more likely to withdraw is important in maximizing the use of resources allocated to education and in supporting the development of retention strategies that help to improve the graduation rate of students.

For these reasons, numerous economic and sociological studies are devoted to students' drop-out behavior (see, e.g., Arulampalam et al., 2001; Blanchfield, 1972; Booth and Satchell, 1995; Bradley and Lenton, 2005; Desjardins et al., 1999; Eckstein and Wolpin, 1999; Ehrenberg and Panagiotos, 1995; Mallete and Cabrera, 1991; Pantages and Creedon, 1978; Siegfried and Stock, 2001; Simpson et al., 1980; Tinto, 1987). Due to the lack of appropriate data, there is no such study for Spain. This article attempts to fill this gap by analyzing the incidence, timing, and determinants of dropping out in higher education. Our results rely on the whole population of first-year entrants in a Spanish university, who were observed over an eight-year period ending in June 2004. Based on this unique data-set, which describes the school career of new entrants in more than 40 academic programs, we estimate discrete-time hazard models of the decision to withdraw in a competing-risk framework. In tracking the educational progress of higher education students, we aim to identify predictors of dropping out, involving students' characteristics, family background, academic experiences, and institutional context. In adressing these questions, the paper contributes to the growing literature on the determinants of dropping out. The results may be suggestive for the individual student, and potentially for university authorities and educational planners in designing policies and initiating interventions to prevent students from leaving higher education.

In brief, the findings indicate that the system's internal efficiency is low and that much room for 
improvement exists, especially in the higher technical school sector, where two-thirds of the entering cohort leave before graduation. We show that students who drop out of higher education have different traits than those who do not. We demonstrate, for example, that students who leave before graduation have fewer abilities and less motivation and that delayed entry into higher education as well as family background and age at enrollment are important factors in explaining students' decision to withdraw from school. In the current context of Spain, where the higher education system has expanded rapidly in the past two decades, the results suggest a need to reexamine and adjust admission policies in higher education and to map plans for providing academic support to at-risk students.

The remainder of the paper is organized as follows. The next section presents a short description of the Spanish higher education sector. The third section describes the data, together with a discussion of the variables. The subsequent section presents the econometric model. The fifth section presents estimates of the determinants of drop-out probabilities based on a competing-risk model. The final section draws some conclusions and policy implications.

\section{Institutional context}

Higher education in Spain offers three distinct tracks that emphasize either academic or vocational subjects. ${ }^{1}$ Students may pursue long-cycle programs offered by the conventional facultades (university faculties). The university faculties account for a little more than $50 \%$ of the students in higher education. University faculties are entitled to offer studies in all branches of knowledge (health sciences, physical and natural sciences, social sciences, humanities, etc.), with the exception of technologies. Long-cycle programs at university faculties last between four and six years, depending on the discipline and the university, and lead to a licenciado degree (licentiate degree). Long-cycle professional programs are offered at the escuelas técnicas superiores (higher technical schools), which lead to ingeniero (engineering) and arquitecto (architectural) degrees and require five to six years of study. Fewer than $10 \%$ of students in higher education are enrolled in higher technical schools. Short-cycle degree programs are offered at the escuelas universitarias (university schools). The studies undertaken at these colleges last three years, and graduates receive the degree of diplomado (university diploma), ingeniero técnico (engineering technician), or diplomado arquitecto técnico (architectural technician). The programs offer a wide range of subjects, including fine arts, information technology, library science, nursing, allied health, social work, business studies, teaching at the basic education level, technical engineering, and architecture. Students who complete short-cycle programs may pursue long-cycle programs. Today, university schools account for $40 \%$ of students enrolled in higher education.

Most long and short programs are based on a credit system. Generally, no strict regulation limits the length of time in which students must complete their courses. In some cases, students are permitted to repeat up to six times in any given subject.

Admission to faculties and higher technical schools is based on the Prueba de Aptitud para la Universidad, an entrance examination conducted by the higher education institutions themselves. ${ }^{2}$ Because of the huge demand for higher education and the limited number of places, nearly all universities in the past few years have established admission quotas for a number of subject areas, using the entrance examination as the basis. As a consequence, students with low scores on the entrance examination may not be admitted to the program of their choice or may be denied entry altogether. Admission to short-cycle degree programs is generally much less selective. Students who have completed the Curso de Orientación Universitaria and students with a vocational education degree may enter a university school without sitting for the entrance examination. However, a system of preselection

\footnotetext{
${ }^{1}$ For more details, see, for example, Postlethwaite (1995) or International Bureau of Education (2006).

${ }^{2}$ Students who sit for the Prueba de Aptitud para la Universidad have completed upper-secondary education and a oneyear period known as the Curso de Orientación Universitaria (university orientation course).
} 
exists for entry into almost all short-cycle programs, with final selection determined on the basis of the results obtained during the Curso de Orientación Universitaria.

At the macro level, very little information is available on the internal efficiency of the Spanish higher education system. No systematic information is collected to follow the schooling career of higher education students, and data published by the Ministry of Education do not make it possible to measure the system's student flow efficiency. In what follows, we put together various pieces of information pertaining mainly to the number of graduates and the time-to-degree by sector (Table 1). The information available nationwide, while admittedly incomplete and imperfect, ${ }^{3}$ suggests a low performance of the higher education system as a whole, and that of the university school sector in particular. According to the Ministry of Education (Ministerio de Educación y Ciencia, 2001), 70\% of the first-year entrants in technical university schools drop out. We estimate that one-third only of the students enrolled in the last year of a higher technical school program graduate, while two-thirds repeat or drop out. In the faculty sector, the ratio of graduates/students is around $11 \%$, while with fixed cohort size this ratio would be roughly $20 \%$ for most programs. ${ }^{4}$ With regard to the time to degree, the results in Table 1 show that only $30 \%$ of the 2003/04 degree recipients were able to graduate within the intended period of time, while nearly $50 \%$ required two more years or more to earn a diploma. Obviously, these patterns tend to indicate that the internal efficiency of the higher education system is low. Taking advantage of the availability of a unique set of longitudinal data, this paper looks closely into the schooling career of a cohort of new entrants into the higher education system and provides estimates of the main determinants of their drop-out behavior.

Table 1. Production of graduates by sector, $2003 / 04^{\mathrm{a}}$.

\begin{tabular}{lcccr}
\hline & $\begin{array}{c}\text { University } \\
\text { faculties }\end{array}$ & $\begin{array}{c}\text { Higher technical } \\
\text { schools }\end{array}$ & $\begin{array}{c}\text { University } \\
\text { schools }\end{array}$ & Total \\
\hline $\begin{array}{l}\text { Graduates/students enrolled in last grade (\%) } \\
\text { Graduates/total enrollment (\%) }\end{array}$ & 57.3 & 35.0 & 35.8 & 43.5 \\
$\begin{array}{l}\text { Drop-out rate (\%) } \\
\text { Time-to-degree }\end{array}$ & 10.6 & 12.9 & 15.3 & 13.7 \\
$\quad$ nd & & nd & $70.0^{\mathrm{b}}$ & nd \\
Graduates by years of graduation (\%) & 6.8 & 7.8 & 4.7 & - \\
$\quad$ & & & & \\
$\quad$ Within the intended time frame & 26.6 & 31.0 & 38.2 & 31.0 \\
$\quad$ One year more & 21.7 & 21.2 & 20.4 & 21.2 \\
$\quad$ Two years more & 16.3 & 15.6 & 13.3 & 15.6 \\
$\quad$ Three years and more & 35.3 & 32.2 & 28.1 & 32.2 \\
\hline
\end{tabular}

Sources: Ministerio de Educación y Ciencia (2001, 2006).

${ }^{\mathrm{a}}$ Unless otherwise indicated.

${ }^{\mathrm{b}}$ Engineering university schools only; the result pertains to the 1995/96 cohort of first-year entrants in 49 institutions (see Ministerio de Educación y Ciencia, 2006, Annex table II-E).

${ }^{\mathrm{c}}$ The data refer to various cohorts of freshmen who graduate during the same school year. The date of entry in the various higher education programs is missing for more than $20 \%$ of the $2003 / 04$ graduates. We address the problem by distributing the missing values in proportion to time to degree; by doing so, we assume that the Registrar's Office has a greater probability of reporting a missing date of entry for cohorts of older students.

\footnotetext{
${ }^{3}$ No information is available on drop out and repetition. Precise information on the distribution of students by grade is also lacking, and the distribution of graduates by year of entry into the program is generally poorly documented.

${ }^{4}$ We consider here that the vast majority of programs in the faculty sector lasts for five years.
} 


\section{Data and variables}

The data cover the full population of first-year entrants at the University of Málaga at the start of the 1996 academic year - that is, around 7000 students enrolled in 46 programs. ${ }^{5}$ These students were observed until June 2004, for a total of about eight full school years. Withdrawal from a course is inferred from enrollment records. Students who have a period of non-enrollment between periods of enrollment are excluded from the analysis, due to data limitations. ${ }^{6}$ Although students may drop out at any time during the academic year, due to data limitations we measure the time until withdrawal as the number of years from the first year of enrollment in the program. Otherwise stated, we know the year in which students drop out, but we do not know the exact date when this event occurs. ${ }^{7}$ Drop out is defined as withdrawal from a degree program for whatever reason. In other words, if a student leaves the program before graduation and switches to another program at the same university, then this student is deemed to have withdrawn; students who leave before completion and transfer to out-of-state institutions are reported as drop outs, although they may eventually enter a higher education program elsewhere. For the students who are still enrolled and have not achieved the degree by the date of our last observation (June 2004), we mark the duration as censored at this point; the duration of this incomplete spell is therefore eight years.

The data for our analysis come from administrative records maintained at the Registrar's Office of the university and from data recorded at the Ministry of Education of the Autonomous Government of Andalusía. Apart from detailed transcript data from first year to drop out or graduation, the database extracted from these registries also describes the personal characteristics and family background of students when they enter the university (age, gender, location, parental education), measures of their secondary educational experience (grade-point average at the time of the pre-university examination; field of study in secondary school), and information on whether the students were accepted into their preferred course of study and whether they received financial support at each point in time.

\section{Incidence of dropping out}

Table 2 presents information about unconditional and conditional drop-out rates for the 1996 cohort of new entrants into higher education. The unconditional drop-out rate is the proportion of first-year entrants who left the program within our study period. The conditional drop-out rate is the proportion of students known to be enrolled at the beginning of a particular year who left by the end of that year. To complete the picture of the schooling career of the cohort, the table also shows the unconditional completion rate of the entering cohort, the percentage of students who were still enrolled in the program before the end of data collection, and the timing of the drop-out decision for those students who quit the program.

The results in Table 2 show that the internal efficiency of higher education is low: $46 \%$ of all students who started a degree in 1996 dropped out, ${ }^{8} 40 \%$ graduated, and $14 \%$ were still enrolled in the program

\footnotetext{
${ }^{5}$ The University of Málaga enrolls more than 38000 students; it is one of the eight largest institutions in the country. Although there is no precise information to compare the performance of students in Málaga, we consider that, overall, this institution is fairly representative of the Spanish higher education system. To illustrate, the graduates/students ratios in the faculty and university school sector are around 13\% at Málaga, compared with 13\% and 15\%, respectively, at the system level (see Table 1). However, higher technical school graduates in Málaga tend to finish more rapidly their studies than their counterparts nationwide. We estimate that around $40 \%$ of graduates in this institution complete their degree within the intended time frame (Lassibille \& Navarro Gómez, 2007); according to the rough information supplied by the Ministry of Education, this proportion is around $30 \%$ at the national level.

${ }^{6}$ We roughly estimate that less than $2 \%$ of entering students stop out during our period of observation.

${ }^{7}$ As pointed out by an anonymous referee, students who drop out during a given year may have different reasons for leaving depending on the exact date when their decision occurs. However, given the nature of our data, we are not able to identify such differentiated effects.

${ }^{8}$ Among these students, we estimate that around one-third switches to another program at the University of Málaga; we are not able to evaluate the proportion of students who transfer to another institution.
} 
at the time of the survey. This overall picture masks a great diversity across types of institutions and programs. In the higher technical schools, where students are admitted on the basis of a very strong competitive examination, more than $60 \%$ of the entering cohort dropped out, and only $12 \%$ obtained their diploma within the eight-year window of observation. Students in university schools perform better, on average, than their peers in higher technical schools. However, it is noteworthy that there is a huge range of outcomes within this sector, with drop-out rates varying between 15 and $64 \%$, depending on the type of program. The university faculties have a better yield, with an overall drop-out rate less than $40 \%$. Even so, there is substantial variation within the subsector-between medical and arts faculties, with unconditional drop-out rates varying between 17 and 28\%; and the other fields of studies, with drop-out rates varying from a low of around $38 \%$ to more than $50 \%$.

Table 2. Schooling caree of new entrants to public higher education, by type of program.

\begin{tabular}{|c|c|c|c|c|c|c|c|c|c|c|c|}
\hline & \multirow[b]{3}{*}{$\begin{array}{l}\text { Duration of the } \\
\text { program (yeas) }\end{array}$} & \multirow[b]{3}{*}{$\begin{array}{l}\text { Number of } \\
\text { observations }\end{array}$} & \multicolumn{6}{|c|}{ Drop-out nate $(\%)$} & \multirow[b]{3}{*}{$\begin{array}{c}\text { Mean time } \\
\text { to drop out } \\
(y e \text { ars) }\end{array}$} & \multirow[b]{3}{*}{$\begin{array}{c}\text { Unconditional } \\
\text { completion rate } \\
\text { (\%) }\end{array}$} & \multirow[b]{3}{*}{$\begin{array}{c}\text { Censored } \\
\text { observations } \\
(\%)\end{array}$} \\
\hline & & & \multicolumn{6}{|c|}{ Conditional } & & & \\
\hline & & & Unconditional & Year I & Year 2 & Year 3 & Year 4 & $\begin{array}{c}\text { Year } 5 \\
\text { and } \\
\text { mote }\end{array}$ & & & \\
\hline \multicolumn{12}{|l|}{ Univer sity faculties" } \\
\hline $\begin{array}{l}\text { Economics and basines } \\
\text { alministration }\end{array}$ & 4 & 588 & 37.9 & 187 & 8.4 & 5.7 & 4.9 & 31 & 2.3 & 44.0 & 18.0 \\
\hline Law & 5 & 574 & 54.5 & 35.2 & 8.1 & 8.8 & 4.8 & 4.4 & 2.0 & 29.3 & 16.2 \\
\hline Total & {$[4,5]$} & 1162 & 46.1 & 26,9 & 82. & 7.1 & 48 & 3,7 & 2.1 & 36.7 & 17.1 \\
\hline Ars and hum an seinces: & 4 & 1429 & 27,9 & 15.0 & 3.8 & 33 & 1.9 & 5.0 & 2.5 & 63.6 & 8.5 \\
\hline Scien ce & 5 & 563 & 53.8 & 32.5 & 10.8 & 7.4 & 5.8 & 4.2 & 2.0 & 28.2 & 17.9 \\
\hline Heal th & 6 & 136 & 16.9 & 6.6 & 2.4 & 2.4 & 25 & 1.6 & 28 & 713 & 118 \\
\hline Taal & {$[4,6]$} & 3290 & 38.3 & 21.8 & 6.2 & 5.0 & 3.4 & 4.1 & 22 & 48.4 & 13.3 \\
\hline \multicolumn{12}{|l|}{ University schools? } \\
\hline $\begin{array}{l}\text { Economics and business } \\
\text { administation }\end{array}$ & 3 & 1101 & 57.2 & 38.0 & 10.0 & 63 & 7.3 & 7,1 & 2.0 & 31.7 & 11.1 \\
\hline Edacation & 3 & 540 & 24.1 & 15.2 & 3.5 & 25 & 4.8 & 10.2 & 1.9 & 74.3 & 1.7 \\
\hline Health & 3 & 219 & 15,1 & 10.0 & 2.5 & 2,1 & 2.0 & 2.2 & 1.7 & 82.6 & 23 \\
\hline Engineerng & 3 & 1049 & 64.4 & 35.2 & 16.5 & 100 & 6.3 & 7.8 & 2.3 & 14.3 & 21.3 \\
\hline Taal & 3 & 2909 & 505 & 30.6 & 10.0 & 61 & 6.3 & 7.6 & 2.1 & 372 & 12.3 \\
\hline Total & {$[3,6]$} & 6991 & 46.1 & 25.7 & 9.5 & 6.4 & 48 & 5.5 & 22 & 396 & 14.3 \\
\hline
\end{tabular}

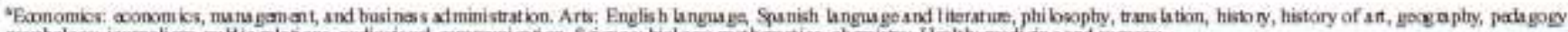

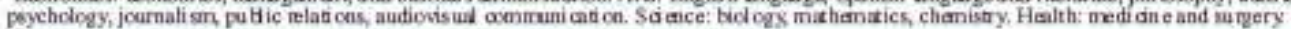

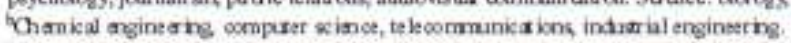

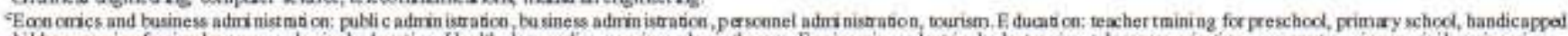

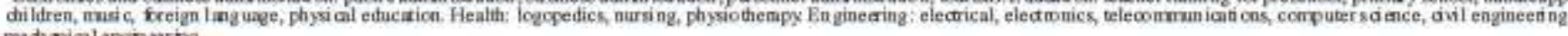
medarical engoering.

Looking more closely into the drop-out pattern by year, results in Table 2 show that the conditional drop-out rate declines quite dramatically as students progress through the program. By the end of the first year, higher education students have a drop-out probability of $26 \%$ compared with $10 \%$ and $6 \%$ by the end of the second and third year, respectively. After three years, the probability is around $5 \%$. These patterns differ widely across institutions, and several features in the data are noteworthy in this regard. First, the propensity to withdraw during the first year is much higher among university school students: $31 \%$ compared with $22 \%$ in university faculties and $24 \%$ in higher technical schools. A second feature is that, compared with their peers, students in higher technical schools are much more likely to leave the program at the end of the second year of studies. As shown in Table 2, their conditional probability of dropping out after two years is $22 \%$, compared with $6 \%$ for students in university faculties and $10 \%$ for students in university schools. In other words, the timing of departures does not display a simple pattern across programs, and significant variations do exist in attrition rates according to time spent in the program, as indicated by the differences observed in the cumulative drop-out probabilities by field of study (Table 3). 


\section{Explanatory variables}

Table 4 presents the summary statistics of the variables for our data-set, with means and standard deviations shown by type of program. In this table, summary statistics for time-independent variables are computed at the student level. For the time-dependent variable, we calculate first the average value over time of the variable for each student and then average this mean value over all students in the sample.

Table 3. Cumulative probabilities of dropping out over time.

\begin{tabular}{lrrrrrrr}
\hline & Year 1 & Year 2 & Year 3 & Year 4 & Year 5 & Year 6 & $\begin{array}{c}\text { Year 7 } \\
\text { and more }\end{array}$ \\
& & & & & & & \\
\hline $\begin{array}{l}\text { University faculties } \\
\quad \text { Social sciences }\end{array}$ & & & & & & & \\
$\quad \begin{array}{l}\text { Economics and business } \\
\text { administration }\end{array}$ & 18.7 & 25.5 & 29.8 & 33.2 & 34.9 & 36.6 & 37.9 \\
$\quad$ Law & 35.2 & 40.4 & 45.6 & 48.3 & 50.5 & 52.4 & 54.5 \\
$\quad$ Total & 26.9 & 32.9 & 37.6 & 40.6 & 42.6 & 44.4 & 46.1 \\
$\quad \begin{array}{l}\text { Arts and human sciences } \\
\text { Science }\end{array}$ & 15.0 & 18.2 & 20.9 & 22.3 & 24.1 & 25.4 & 27.9 \\
$\quad$ Health & 32.5 & 39.8 & 44.2 & 47.4 & 49.7 & 52.4 & 53.8 \\
$\quad$ Total & 6.6 & 8.8 & 11.0 & 13.2 & 13.2 & 16.2 & 16.9 \\
Higher technical schools & 21.8 & 26.7 & 30.4 & 32.7 & 34.6 & 36.4 & 38.3 \\
University schools & 23.6 & 40.4 & 48.9 & 53.2 & 55.8 & 58.6 & 62.5 \\
$\quad$ Economics and business & & & & & & & \\
$\quad$ administration & 38.0 & 44.1 & 47.7 & 51.0 & 52.9 & 54.7 & 57.2 \\
$\quad$ Education & 15.2 & 18.1 & 20.2 & 21.5 & 22.6 & 23.3 & 24.1 \\
$\quad$ Health & 10.0 & 12.3 & 14.2 & 14.6 & 14.6 & 14.6 & 15.1 \\
$\quad$ Engineering & 35.2 & 45.9 & 51.3 & 54.3 & 57.4 & 60.7 & 64.4 \\
$\quad$ Total & 30.6 & 37.5 & 41.4 & 44.0 & 46.0 & 48.0 & 50.5 \\
Total & 25.7 & 32.8 & 37.0 & 39.7 & 41.7 & 43.7 & 46.1 \\
\hline & & & & & & & \\
\hline
\end{tabular}

According to Table 4, the three types of higher education institutions serve different clientele. Higher technical schools enroll a much higher proportion of male students compared with university faculties and university schools. In Spain, the official starting age for higher education is 18. Results in Table 4 indicate that the average age of entry into a university school program exceeds this standard by two years and that first entrants into long programs are comparatively younger and fresh from their secondary education. Our data-set makes it possible to evaluate whether a student has experienced discontinuity between completion of secondary school and enrollment in higher education. Results show that university school students are particularly prone to postpone enrollment after completing upper-secondary or vocational education: $18 \%$ of new entrants in short programs are delayers, compared with $8 \%$ of new entrants in university faculties and 3\% of new entrants in higher technical schools. Parental education is often found to be one of the most important family-related factors in explaining dropping out (see, e.g., Manski et al., 1999; Smith and Naylor, 2001). In this regard, a striking aspect of the information in Table 4 is that students enrolled in long-cycle programs tend to come from more advantaged families, as seen by the relatively small number of fathers with only a primary or a lowersecondary education. In addition, a student's ability and motivation are crucial determinants of dropping out. We use scores achieved on the pre-university examination to control for students' pre-enrollment academic abilities. Since selection and entry requirements differ widely by subject and because students 
differ widely in ability, we normalize the scores within subject. ${ }^{9}$ In other words, we measure each person's performance relative to the mean score of his or her peers. In a system based on entrance quotas, many students do not get into their first choice of course at the university. Because the system may create potential frustration and dissatisfaction among applicants, it may increase their probability of dropping out. Results in Table 4 indicate that $41 \%$ of students enrolled in short programs are not satisfied with the subject they are enrolled in, compared with $34 \%$ of first-year students in university faculties and $24 \%$ of first-year students in higher technical schools. Turning now to the time-varying enrollment variable, which represents information available after students have enrolled at a particular institution, Table 4 shows that the share of students receiving grant support during their schooling career ranges between $22 \%$ and $40 \%$, depending on the type of program. ${ }^{10}$ Information that is not shown here to save space indicates that the proportion of grant holders decreases dramatically over time-from 53\% in the first year to less than $25 \%$ at the end of the third year, for example.

Table 4. Means and standard deviations of selective variables in the sample.

\begin{tabular}{|c|c|c|c|c|c|c|}
\hline & \multicolumn{2}{|c|}{$\begin{array}{l}\text { University } \\
\text { faculties }\end{array}$} & \multicolumn{2}{|c|}{$\begin{array}{l}\text { Higher technical } \\
\text { schools }\end{array}$} & \multicolumn{2}{|c|}{$\begin{array}{l}\text { University } \\
\text { schools }\end{array}$} \\
\hline & Mean & $\begin{array}{l}\text { Standard } \\
\text { deviation }\end{array}$ & Mean & $\begin{array}{l}\text { Standard } \\
\text { deviation }\end{array}$ & Mean & $\begin{array}{l}\text { Standard } \\
\text { deviation }\end{array}$ \\
\hline \multicolumn{7}{|l|}{ Time variable } \\
\hline$t=1$ & 0.218 & 0.413 & 0.228 & 0.419 & 0.278 & 0.448 \\
\hline$t=2$ & 0.171 & 0.377 & 0.174 & 0.379 & 0.193 & 0.394 \\
\hline$t=3$ & 0.159 & 0.367 & 0.136 & 0.343 & 0.174 & 0.379 \\
\hline$t=4$ & 0.152 & 0.359 & 0.117 & 0.321 & 0.115 & 0.319 \\
\hline$t \geq 5$ & 0.299 & 0.458 & 0.346 & 0.476 & 0.240 & 0.427 \\
\hline \multicolumn{7}{|l|}{ Study program } \\
\hline Economics and business administration & 0.179 & 0.383 & - & - & 0.378 & 0.485 \\
\hline Law & 0.175 & 0.380 & - & - & - & - \\
\hline Arts and human sciences ${ }^{a}$ & 0.435 & 0.496 & - & - & 0.186 & 0.389 \\
\hline Science & 0.171 & 0.377 & - & - & - & - \\
\hline Health & 0.041 & 0.199 & - & - & 0.075 & 0.264 \\
\hline Engineering & - & - & - & - & 0.361 & 0.480 \\
\hline Male & 0.383 & 0.486 & 0.795 & 0.404 & 0.492 & 0.500 \\
\hline Age at enrollment (years) & 18.803 & 1.906 & 18.261 & 0.899 & 20.156 & 2.997 \\
\hline Delayed enrollment & 0.084 & 0.278 & 0.033 & 0.178 & 0.180 & 0.384 \\
\hline $\begin{array}{l}\text { Normalized score on the pre-university } \\
\text { examination }\end{array}$ & 0.000 & 1.000 & 0.000 & 1.000 & 0.000 & 1.000 \\
\hline $\begin{array}{l}\text { Entering with a vocational education } \\
\text { diploma }\end{array}$ & - & - & - & - & 0.370 & 0.483 \\
\hline Studying chosen subject & 0.664 & 0.472 & 0.761 & 0.427 & 0.594 & 0.491 \\
\hline Receiving state financial support ${ }^{b}$ & 0.297 & 0.373 & 0.223 & 0.333 & 0.399 & 0.417 \\
\hline \multicolumn{7}{|l|}{ Parents' characteristics } \\
\hline Primary education completed or less & 0.396 & 0.489 & 0.340 & 0.474 & 0.583 & 0.493 \\
\hline Lower-secondary education & 0.127 & 0.332 & 0.133 & 0.339 & 0.133 & 0.340 \\
\hline Upper-secondary education & 0.097 & 0.296 & 0.131 & 0.338 & 0.088 & 0.284 \\
\hline Higher education & 0.229 & 0.420 & 0.369 & 0.483 & 0.126 & 0.332 \\
\hline Unknown & 0.151 & 0.359 & 0.028 & 0.164 & 0.070 & 0.255 \\
\hline Resident of the institution's home town & 0.520 & 0.500 & 0.426 & 0.495 & 0.483 & 0.500 \\
\hline Number of students & 3288 & - & 792 & - & 2909 & - \\
\hline Number of student-period records & 15070 & - & 3476 & - & 10453 & - \\
\hline
\end{tabular}

${ }^{a}$ The category of arts and human sciences in university schools includes education only (teacher training for preschool, primary school, handicapped children, music, foreign language, physical education).

'Time-dependent variable.

\footnotetext{
${ }^{9}$ Normalized score at pre-university examination $=(X-M) / S$, where $X$ is the student's score on the pre-university examination, $M$ is the average score of students taking the same subject, and $S$ is the standard deviation.

${ }^{10}$ The amount of financial aid students received is not available in the data-set.
} 


\section{Econometric specification}

This section describes the econometric methods for estimating the determinants of the decision to drop out. Time is discrete and measured in years. We know the year in which students dropped out or graduated, but we do not know the exact date when these events occurred. Discrete-time hazard analysis can be used to study this type of data. Following tradition (see, e.g., Singer and Willet, 1993; Willet and Singer, 1991), we estimate a proportional odds model and assume that the relative odds of making a transition in year $t$, given survival up to the end of the previous year, is summarized by an expression of the form:

$$
\frac{h\left(t, X_{t}\right)}{1-h_{\left(t, X_{t}\right)}}=\left[\frac{h_{0}(t)}{1-h_{0}(t)}\right] \exp \left(\beta X_{t}\right)
$$

or equivalently:

$$
\log \operatorname{it}\left[h\left(, X_{t}\right)\right]=\log \left[\frac{h(t)}{1-h(t)}\right]=\alpha_{t}+\beta X_{t}
$$

where $X_{t}$ is a vector of time-invariant and time-varying covariates, $\beta$ is a vector of regression coefficients, $h\left(t, X_{t}\right)$ is the discrete-time hazard rate for year $t, h_{0}\left(t, X_{t}\right)$ is the corresponding baseline hazard arising when $\mathrm{X}_{\mathrm{t}}=0$, and $\alpha_{\mathrm{t}}=\log \mathrm{it}\left[\mathrm{h}_{0}(\mathrm{t})\right]$ is the logit of the baseline hazard function. Changes in $h(t)$ over time are specified as a piecewise-constant function - that is, a step function of t. Failure to control for any unobserved individual-specific effects that may affect the hazard function can produce severe bias in the structural estimates of duration models (see, e.g., Allison, 1982; Lancaster, 1990; Sheps and Menken, 1973; Vaupel and Yashin, 1985). For this purpose, we extend the previous model by including a random error term along with the vector of characteristics, and we allow for unobserved heterogeneity or frailty by assuming that log odds of the hazard take the form:

$$
\frac{h\left(t, X_{\lambda} \mid e\right)}{1-h_{\left(t, X_{\lambda} \mid e\right)}}=\left[\frac{h_{0}(t)}{1-h_{0}(t)}\right] \exp \left(\beta X_{t}+e\right)
$$

This leads to the model with:

$$
\log \operatorname{it}\left[h\left(t, X_{t}\right) \mid e\right]=\alpha_{t}+\beta X_{t}+e_{t}
$$

where $e_{t}$ is an error term that is normally distributed with mean zero and finite variance $\sigma^{2}$.

A student graduates, drops out, or is censored - that is, he remains in education. Otherwise stated, dropping out and graduating are reasons for students to leave the educational system. We assume that the hazards of each competing risk are mutually independent - that is, we fit the discrete-time proportional hazard model presented above by running separate logistic regressions for the probability of drop out, treating the other event as censored (see Allison, 1982, 1984). To do so, we reorganize the original sample by expanding the data into person-period form, ${ }^{11}$ and we create destination-specific censoring indicators (Prentice and Gloeckler, 1978; Meyer, 1990). The analysis includes all students,

\footnotetext{
${ }^{11}$ The final data-set contains 28999 person-period records on 6991 persons.
} 
and a panel of individuals is constructed with the $i$ th individual contributing $j=1,2, \ldots, \mathrm{t}_{\mathrm{i}}$ observations. The maximum number of periods (years) that an individual can be at risk is eight. Students who graduate are censored at graduation, while students who have neither dropped out nor graduated by the end of data collection are also censored, but at the end of data collection.

\section{Empirical results}

Following the analytical framework described in the previous section, we present the empirical results in two parts. The first describes the estimation procedure used to discriminate between various specifications. The second part discusses the results of the models.

\section{Estimation procedure}

The results presented in Table 5 show separate regressions of the probability of dropping out for each type of higher education institution. Coefficient estimates are reported as odds ratios; values above 1.0 identify predictors that increase the risk of drop out. The models include the time-independent and the time-varying variables discussed in the second section; they employ a general specification of time using a separate dummy variable for each time period. The models are fitted without and with unobserved heterogeneity. We assume that the unobserved individual effects in the frailty models have a Gaussian distribution with mean zero. The log-likelihood of the models and their derivatives are computed using the adaptative Gauss-Hermite method with 12 quadrature points. Results, which are not reported here to save space, show that this quadrature approximation is stable when refitting the random-effects models with more integration points, and that it yields more robust results than the nonadaptative Gauss-Hermite method. ${ }^{12}$ The $\sigma$ coefficients reported in Table 5 are standard deviations of the heterogeneity variances. The reported $\rho$ are the proportions of the total variance contributed by the panel-level variance component. ${ }^{13}$

\begin{tabular}{|c|c|c|c|c|c|c|}
\hline & \multicolumn{2}{|c|}{ University faculties } & \multicolumn{2}{|c|}{ Higher technical schools } & \multicolumn{2}{|c|}{ University schools } \\
\hline & $\begin{array}{c}\text { Without } \\
\text { unobserved } \\
\text { heterogeneity }\end{array}$ & $\begin{array}{c}\text { With } \\
\text { undbserved } \\
\text { heterogeneity }\end{array}$ & $\begin{array}{c}\text { Without } \\
\text { unobserved } \\
\text { heterogeneity }\end{array}$ & $\begin{array}{c}\text { With } \\
\text { unobserved } \\
\text { heterogeneity }\end{array}$ & $\begin{array}{c}\text { Without } \\
\text { undbserved } \\
\text { heterogeneity }\end{array}$ & $\begin{array}{c}\text { Wirh } \\
\text { unobsened } \\
\text { heterogeneity }\end{array}$ \\
\hline \multicolumn{7}{|l|}{ Time varible } \\
\hline$t=2$ & $0.204^{* * *}$ & $0.206 * \cdots$ & 0.878 & 0.937 & $0.216 * \cdots$ & $0.222 * * *$ \\
\hline$t=3$ & $0.166 * * *$ & $0.172^{* * *}$ & $0.552^{* * *}$ & $0.618^{* * * *}$ & $0.133 * * *$ & $0.140^{* * *}$ \\
\hline$t=4$ & $0.110^{* * *}$ & $0.115 * * *$ & $0.316 * * *$ & $0.364 * * *$ & $0.112 * * *$ & $0.121^{* * *}$ \\
\hline $1 \geq 5$ & $0.111^{* * t}$ & $0.121 * \cdots$ & $0.232 * \cdots$ & $0.280 * * *$ & $0.124 * \cdots$ & $0.140 * \cdots$ \\
\hline \multicolumn{7}{|l|}{ Study program ${ }^{a}$} \\
\hline Law & $1.791 * * *$ & $1895 * \cdots$ & - & - & - & - \\
\hline Arts and human sciences ${ }^{b}$ & $0.644^{* * *}$ & $0.623 * * *$ & - & - & $0.338^{* * *}$ & $0.312 * * *$ \\
\hline Science & $1.711^{* * *}$ & $1.788^{* * *}$ & - & - & - & - \\
\hline Health & $0,400^{* * *}$ & $0,382 * \cdots$ & - & - & $0.225 * \cdots$ & $0.207 * \cdots$ \\
\hline Engincering & - & - & - & - & $1.225 * * *$ & $1.245 * *$ \\
\hline Male & 1,085 & 1,094 & $1.269^{*}$ & $1303^{*}$ & 1.033 & 1037 \\
\hline Age at enrollment (years) & $1.090 * * *$ & $1.103 * \cdots$ & $1.147^{* *}$ & $1.165 * 0$ & $1054 * \cdots$ & $10600^{* *+*}$ \\
\hline Delayed enrdinent & $1.353^{* * 0}$ & $1.369 * *$ & 0.882 & 0.893 & $1.244 * * *$ & $1239 * *$ \\
\hline Normalized score at pre-university examination & $0.637^{* * *}$ & $0.620^{* * *}$ & Q.593*** & $0.562^{* * *}$ & $0.802^{* * *}$ & $0.786^{* * *}$ \\
\hline Ente ring with a vocational education diploma & - & - & - & - & $2.651 \cdots$ & $2.901^{* \cdots *}$ \\
\hline Sudyng dosen subject & $0.809 * * *$ & $0.784^{* * *}$ & 0.974 & 0.971 & $0.732 * \cdots$ & $0.709 * \cdots$ \\
\hline Receiving state financial spport & $0.489 * * *$ & $0.469 * \cdots$ & $0.660 * \cdots$ & $0.643 * \cdots$ & $0.621 \cdots$ & $0.607 * * *$ \\
\hline \multicolumn{7}{|l|}{ Parents' characteristics } \\
\hline \multicolumn{7}{|l|}{ Father'seducation levef' } \\
\hline Lav er-secondary education & 1.055 & 1.053 & 1.041 & 1.022 & $0.930^{* * *}$ & $0.929 * \cdots$ \\
\hline Uppet-secondary education & 0.875 & 0.867 & 1.204 & 1.206 & 0.872 & 0.856 \\
\hline
\end{tabular}

\footnotetext{
12 When using the non-adaptative Gauss-Hermite quadrature, the coefficients of the variables change with a relative difference up to $167 \%$ between the models with 12 and 16 integration points. With the adaptative Gauss-Hermite quadrature, these relative differences are less than $5 \%$.

${ }^{13} \rho=\sigma_{u}{ }^{2} /\left(\sigma_{u}{ }^{2}+\sigma_{\varepsilon}{ }^{2}\right)$, where $\varepsilon$ are logistic, independent and identically distributed with mean zero and variance $\sigma_{\varepsilon}{ }^{2}=\pi^{2} / 3$.
}

Why do higher education students drop out? Evidence from Spain 


\begin{tabular}{|c|c|c|c|c|c|c|}
\hline & \multicolumn{2}{|c|}{ University faculties } & \multicolumn{2}{|c|}{ Higher tedinical schook } & \multicolumn{2}{|c|}{ Universiry schools } \\
\hline & $\begin{array}{c}\text { Without } \\
\text { unobserved } \\
\text { herogendity }\end{array}$ & $\begin{array}{c}\text { With } \\
\text { unobserved } \\
\text { heterogeneity }\end{array}$ & $\begin{array}{c}\text { Witbout } \\
\text { unobserved } \\
\text { herarogeneity }\end{array}$ & $\begin{array}{c}\text { With } \\
\text { unobserved } \\
\text { heterogeneity }\end{array}$ & $\begin{array}{l}\text { Winhout } \\
\text { unobserved } \\
\text { heterogendity }\end{array}$ & $\begin{array}{c}\text { With } \\
\text { unobserved } \\
\text { hererogencity }\end{array}$ \\
\hline Higher alucation & $0.757 * * *$ & $0.742 * *$ & $0.742^{* *}$ & $0,713 * \bullet$ & 0.852 & 0.847 \\
\hline Resident of the institution's home town & $0.894^{*}$ & 0886 & $0.770^{* *}$ & $0.748 * *$ & 1020 & 1.089 \\
\hline$\sigma_{u}$ & - & $1599 * * 0$ & - & $0.535 * \cdots$ & - & $1.434 * * 0$ \\
\hline$\rho$ & - & 0.437 & - & 0,080 & - & 0.384 \\
\hline Likelihood matio for $\rho$ & - & $18.949 * * *$ & - & $1.686^{*}$ & - & $12.181 * * *$ \\
\hline Model $x^{2}$ & $1475.273 * * *$ & $802.136 * \cdots$ & $315.518 * * *$ & $232.732 * * \bullet$ & $1390.370^{* * *}$ & $738.715 * \cdots$ \\
\hline Preudo $R^{2}$ & 0.170 & - & 0.111 & - & 0.164 & - \\
\hline Number of student-period records & 15030 & 15030 & 3476 & 3476 & 10453 & 10.453 \\
\hline Number of students & - & 3288 & - & 792 & - & 2909 \\
\hline
\end{tabular}

The model chi-square statistics indicate that the regressions are significant at standard levels. The likelihood ratio tests for $\rho$ in Table 5 suggest statistically significant frailty with a non-negligible panellevel variance component. This result implies that ignoring unobserved heterogeneity may lead to misleading conclusions about the determinants and the timing of the decision to drop out. As shown in Table 5, the estimated coefficients on the regressors other than the time dummies are generally larger in magnitude than the corresponding coefficients in the non-frailty models. Also, the duration dependence is smaller in absolute value in the frailty models than in the reference models - that is, the baseline hazard slopes downward to a smaller extent. Thus, in the remainder of this discussion, we focus on the results that take into account unobserved heterogeneity.

\section{Correlates of dropping out}

The results show that, all else remaining the same, there is significant duration dependence in the withdrawal rate, with the rate being highest in the first year and decreasing in successive years - except for students in higher technical schools, who are at the same risk of dropping out in their first two years of studies. Regarding study programs, students in health have lower hazard rates, lower conditional withdrawal rates, and hence longer survival time compared with their peers in both university faculties and university schools. A noteworthy feature in the results is that students in law, sciences, and engineering experience a relative risk of dropping out between 1.2 and 1.9 times higher than their counterparts, ceteris paribus. Overall, these findings are consistent with the descriptive analysis performed in the second section.

While there is no significant gender effect among students in university faculties and university schools, male students in higher technical schools are more likely to drop out than their female counterparts. ${ }^{14}$ All else remaining the same, the odds of dropping out for female students in higher technical schools is about $80 \%$ that of male students.

With regard to the impact of age at enrollment, results in Table 5 suggest that, for all three sets of students being compared, the variable is positively associated with dropping out. This result is consistent with the findings from other studies on the determinants of withdrawal from post-compulsory education (see, e.g., Deike, 2003; Desjardins et al., 1999; or Murtaugh et al., 1999). However, the impact of age differs widely by type of institution. Among students in higher technical schools, the odds of dropping out increase by about $17 \%$ with each additional year of age, compared with $10 \%$ for students in university faculties and $6 \%$ for students in university schools. Delaying entry to higher education

\footnotetext{
${ }^{14}$ We tested for possible interaction effects between gender and study programs; none of the coefficients of the interactions was individually significant at standard levels. These results may be obtained from the authors on request.
} 
significantly increases the probability of dropping out among university faculty and university school students, ceteris paribus. According to our results, the relative risk of withdrawal for a university faculty student is $50 \%$ higher than it would be if the student had started on track. Those who delay enrollment in university schools increase their relative probability of dropping out by $44 \%$. These findings are at odds with the commonly held belief that such a pattern of enrollment is associated with socioeconomic constraints and academic marginality that are detrimental to the student's chances of graduation (see, e.g., Bozick and DeLuca, 2005; Hearn, 1992; Jacobs and King, 2002). However, delaying entry into higher education is not found to be an important determinant of withdrawal among students in higher technical schools. This result does not necessarily mean that discontinuity in the schooling career of students in higher technical schools has no consequences; rather, it probably means that very few students in higher technical schools posptone entry.

With regard to the other influences on the probability of dropping out, the regression results indicate that pre-enrollment academic abilities, as measured by the score on the pre-university examination, are a powerful predictor of the probability of withdrawal. All else remaining the same, an advantage of one standard deviation above the sample mean in the pre-university examination score reduces the risk of dropping out to $62 \%$ for students in university faculties, to $56 \%$ for students in higher technical schools, and to $79 \%$ for students in university schools. This is an important conclusion in the Spanish context, where the volume of students who leave secondary education with a diploma is expected to increase in the future, in response to policies recently introduced to ensure that a larger proportion of students complete their secondary education. In light of our results, reducing the entry standards to satisfy the demand for higher education from an increasing pool of secondary-school leavers who are not necessarily equipped with the basic skills needed to succeed in higher education would have adverse effects, mainly in university schools. In this context, tighter selection at the entry point of higher education might be needed. As described in the third section of this paper, about one-third of entering students in university schools gain admission following secondary vocational education, while the other two-thirds enroll in short higher education programs after completing general secondary education. According to Table 5, students entering with a vocational education diploma perform significantly worse than their counterparts, with a relative risk of dropping out that is three times greater than that of students who enter with a secondary general education. Obviously, this huge gap raises serious questions about the capacity of the vocational education system to prepare students adequately for higher education studies.

An equally important result is that students who did not get into the course they wanted are at higher risk of leaving the institution before completing their degree, ceteris paribus. We estimate that the odds of withdrawal is between 1.3 and 1.4 times greater for dissatisfied students than for students who are in their preferred course of study, the precise magnitude depending on the type of program. Obviously, this evidence raises questions about the effectiveness of the placement of students and shows that current admission policies do not reduce the risk of dropping out.

Turning now to financial support, the results show that students who receive state grants are less likely than students who do not receive state grants to withdraw in any period. According to this result, financial support not only boosts the demand for education, by reducing the opportunity cost of studies, but also helps to increase the flow of graduates from a given cohort of entering students. This result is consistent with other findings documenting the impact of financial aid on college behavior (see, e.g., Cabrera et al., 1992; Dynarski, 1999; or Edlin, 1993). However, our results show that the sensitivity of dropping out to policies that aim to support students varies widely across sectors. All else remaining the same, the relative risk of dropping out in any given year in the university faculty sector is 2.1 times greater for students without grants than for students with financial support. With an odds ratio for nongranted students of about 1.6, spending on student scholarships appears to be comparatively less effective in reducing the drop-out rate in both the higher technical school sector and the university school sector than in the university faculty sector.

Because financial support is a time-dependent variable, we can make assumptions about the type of 
support that individuals receive during their schooling career. In what follows, we consider three types of students. The first refers to individuals who never received a grant during their schooling career. The second category includes students who received support continuously through the entire period. The third group refers to individuals who received a grant during the first two years of their schooling career only. As shown in Table 6, students who received a grant continuously have a probability of withdrawal between 12 and 17 percentage points lower than students who never received a grant during their schooling career, ceteris paribus. However, supporting students at the beginning of their career increases only slightly the probability of dropping out with respect to a program that aims to support students through their entire period. Depending on the program, the increase varies between four and seven percentage points. This means that, in a context where there is no shortage of qualifications, expanding support to a larger number of students and limiting this support to the beginning of their schooling career could be more effective than a policy supporting a smaller number of students during their entire schooling career.

Table 6. Predicted probability of dropping out, by type of financial support received.

\begin{tabular}{lccc}
\hline & University faculties & Higher technical schools & University schools \\
\hline $\begin{array}{l}\text { Receiving grants } \\
\text { continuously (1) }\end{array}$ & 20.3 & 43.3 & 25.0 \\
$\begin{array}{l}\text { Never receiving a grant } \\
\text { during the period (2) }\end{array}$ & 36.9 & 58.5 & 36.8 \\
$\begin{array}{l}\text { Receiving a grant during the } \\
\text { first two years (3) }\end{array}$ & 25.3 & 50.2 & 28.5 \\
$(2)-(1)$ & 16.6 & 15.0 & 11.8 \\
$(3)-(1)$ & 5.0 & 6.9 & 3.5 \\
\hline
\end{tabular}

Father's level of education accounts for the genetic ability of students and serves also as a predictor of the parent's potential market earnings that could be invested in schooling. Results in Table 5 show that this variable tends to exert a non-linear effect on withdrawal and that first- generation studentsthat is, students whose parents did not graduate from higher education - have a higher probability of withdrawal, ceteris paribus. Among university faculty and higher technical school students, the risk of dropping out for individuals whose father has a higher education diploma is about $70 \%$ of that for students whose father has a primary or secondary education diploma. A noteworthy feature in the results is that there is no significant intergenerational benefit among university school students. This result is possibly because a large proportion of students in this sector come from more disadvantaged backgrounds.

Finally, the results show that students who are not residents of the institution's home town are more likely to drop out than students who are residents, ceteris paribus. In the university faculty and higher technical school sectors, the odds of withdrawal for resident students are about $89 \%$ and $75 \%$ that of non-resident students, respectively. The intuition of this result is clear if we think about constraints on the student's available time. On average, non-resident students have to spend more time traveling and performing domestic tasks than their peers. As shown by Dolton et al. (2003), the time allocated to these activities is not available for study so it has a negative impact on educational achievement. According to our results, it contributes significantly to dropping out.

\section{Conclusions}

In this paper, we have applied discrete-time survival analysis to explain why higher education students drop out. The data for our analysis come from administrative records for the full cohort of first- 
time entering students who enroll in short and long programs at a large public university. Their enrollment histories were observed over an eight-year period ending in June 2004. Although the study was conducted with data from a single institution, they shed light on the drop- out behavior of students. As indicated previously, our results pertain to students enrolled in more than 40 different programs, and for this reason it is very unlikely that our conclusions reflect differences in the nature of graduate programs offered at this one institution.

When describing the data, we found that the incidence of dropping out is particularly high in Spain. At the time of the survey, around $40 \%$ of students who embark on a university faculty program leave before graduating. These proportions are $63 \%$ and $50 \%$, respectively, for first-year entrants in higher technical school and university school programs. We also found that, as students progress through the program, their conditional probability of withdrawal decreases dramatically. To illustrate, $56 \%$ and $15 \%$ of students who drop out leave the program in the first and second year after enrollment, respectively.

Among other results, we have found that, all else remaining the same, academic preparedness and age at enrollment are powerful indicators of withdrawal, regardless of the program of study. Students who delay entry into higher education, as well as students who did not get into the course they wanted, are at higher risk of leaving the program. We have also shown that university school students entering with a vocational education diploma are not sufficiently equipped with the basic skills needed to succeed in higher education. As other empirical studies conducted on the topic have shown, we found that students who receive financial support have lower drop-out rates than students who do not receive support, ceteris paribus, and that the impact of financial support is particularly important at the beginning of the schooling career. Finally, our results have shown that, after controlling for ability, preferences and socioeconomic characteristics, significant differences do exist across subject areas. Obviously these findings raise important questions about the management of the pedagogical processes in the various fields of studies, and clearly more research and more data are needed to analyze this issue.

Several implications for the development of education policy arise from our results. The first is the need for continued efforts to raise survival rates in higher education. In this regard, universities could design and develop retention and graduation interventions for at-risk students; such targeted programs would benefit both the students and the institutions. One main implication from our results is that any academic support plan designed to improve completion should try to reduce the withdrawal rates of atrisk students in the early stage of the program, by stimulating their effort and performance from the beginning of their schooling career. To help increase the flow of graduates from a given cohort of students, policy-makers could consider administrative measures such as more systematic and tighter criteria for selecting the intake into higher education. In this regard, admission of students with a vocational educational diploma could be limited to students with good prior academic performances. Strict measures designed to limit the excessive length of time students are allowed, until now, to complete their courses should also be considered. These interventions could improve the system's performance. In the context of a meaningful expansion of the number of high school graduates, they could also be one way to manage the increased pressures put upon the higher education system.

\section{Acknowledgements}

The research was funded in part through a research support grant from the Ministry of Education (No. SEC2003-08855-C03-01). The opinions expressed in this paper are those of the authors alone and should not be attributed to the institutions with which they are associated. 


\section{References}

Allison, P.D. 1982. Discrete-time methods for the analysis of event histories, in: S. Leinhardt (Ed.) Sociological Methodology, 61-98 San Francisco, CA: Jossey-Bass.

Alliso, P.D. 1984. Event History Analysis. Newbury Park, CA: Sage.

Arulampalam, W. et al. 2001. A hazard model of the probability of medical school dropout in the United Kingdom. IZA DP 333 Bonn: IZA and University of Warwick.

Blanchfield, W. 1972. College dropout identification: an economic analysis. Journal of Human Resources 7, no. 4: 540-44.

Booth, A.L. and S.E. Satchell. 1995. The hazards of doing a PhD: an analysis of completion and withdrawal rates of British PhD students in the 1980s. Journal of the Royal Statistical Society. Series A (Statistics in Society) 158: 297-318.

Bozick, R. and S. DeLuca. 2005. Better late than never? Delayed enrollment in the high school to college transition. Social Forces 84, no. 1: 531-54.

Bradley, S. and P. Lenton. 2005. Dropping out of post-compulsory education in the UK: an analysis of determinants and outcomes. Working Paper, Department of Economics, Management School, Lancaster University.

Cabrera, A.F. et al. 1992. The role of finances in the persistence process: a structure model. Research in Higher Education 33, no. 5: 571-93.

Deike, R.C. 2003. A study of college student graduation using discrete-time survival analysis. PhD Dissertation, Pennsylvania State University.

Desjardins, S.L. et al. 1999. An event history model of student departure. Economics of Education Review 18: 375-90.

Dolton, P. et al. 2003. The effective use of student time: a stochastic frontier production function case study. Economics of Education Review 22: 547-60.

Dynarski, S.M. 1999. Does aid matter? Measuring the effect of student aid on college attendance and completion. Working Paper 7422. Cambridge, MA: National Bureau of Economic Research.

Eckstein, Z. and K. Wolpin. 1999. Why youths drop out of high school: the impact of preferences, opportunities, and abilities. Econometrica 67, no. 6: 1295-339.

Ehrenberg, G.R. and M.G. Panagiotos. 1995. Doctoral students' financial patterns affect their timeto- degree and completion probability. Journal of Human Resources 30: 581-609.

Edlin, A. 1993. Is college financial aid equitable and efficient? Journal of Economic Perspectives 7 , no. 2: $143-58$.

Hearn, J. 1992. Emerging variations in postsecondary attendance patterns: an investigation of parttime delayed and nondegree enrollment. Research in Higher Education 33: 657-87.

International Bureau of Education 2006. World data on education: Spain. Available at http://www.ibe.org (accessed 10 March 2006).

Jacobs, J.A. and R.B. King. 2002. Age and college completion: a life-history analysis of women aged 15-44. Sociology of Education 75: 211-30.

Lancaster, T. 1990. The Econometric Analysis of Transition Data. Econometric Society Monograph. New York: Cambridge University Press.

Lassibille, G. and L. Navarro Gómez. 2007. How long does it take to earn a higher education degree in Spain? Working Paper, Institut de Recherche sur l'Economie de l'Education, Dijon.

Mallete, B.I. and A.F. Cabrera. 1991. Determinants of withdrawal behavior: an exploratory study. Research in Higher Education 32, no. 2: 179-94.

Manski, B.I. et al. 1999. Alternative estimates of the effects of family structure during adolescence on high school graduation. Journal of the American Statistical Association 87, no. 417: 25-37.

Meyer, B.D. 1990. Unemployment insurance and unemployment spells. Econometrica 58: 757-82. Ministerio de Educación y Ciencia 2001. Informe transversal del rendimiento académico de las ingenierías técnicas. Madrid: Consejo de Universidad. 
Ministerio de Educación y Ciencia 2006. Estadística universitaria: Curso 2003-2004. Madrid: Consejo de Coordinación Universitaria.

Murtaugh, P.A. et al. 1999. Predicting the retention of university students. Research in Higher Education 40, no. 3: 355-71.

Pantages, T.J. and C.F. Creedon. 1978. Studies of college attrition: 1950-1975. Review of Educational Research 48, no. 1: 49-101.

Postlethwaite, T.N. 1995. International Encyclopedia of National Systems of Education, 2nd ed. Oxford: Pergamon Press.

Prentice, R. and L. Gloeckler, 1978. Regression analysis of grouped survival data with application to breast cancer data. Biometrics 34: 57-67.

Sheps, M.C. and J.A. Menken. 1973. Mathematical Models of Conception and Birth Chicago, IL: University of Chicago Press.

Siegfried, J.J. and W.A. Stock. 2001. So you want to earn a Ph.D. in economics? How long do you think it will take? Journal of Human Resources 36, no. 2: 364-78.

Simpson, C. et al. 1980. Conventional failures and unconventional dropouts: comparing different types of university withdrawals. Sociology of Education 53: 203-14.

Singer, J.D. and J.B. Willet, 1993. It's about time: using discrete-time survival analysis to study duration time of events. Journal of Educational Statistics 18, no. 2: 155-95.

Smith, J. and R. Naylor. 2001. Determinants of degree performance in U.K. universities: a statistical analysis of the 1993 student cohort. Oxford Bulletin of Economics and Statistics 63, no. 1: 29-60.

Tinto, V. 1987. Leaving College: Rethinking the Causes and Cures of Student Attrition Chicago, IL: University of Chicago Press.

Vaupel, J.W. and A.I. Yashin. 1985. Heterogeneity's ruses: some surprising effects of selection on popula- tion dynamics. American Statistician 39: 176-85.

Willet, J.B. and J.D. Singer. 1991. From whether to when: new methods for studying student dropout and teacher attrition. Review of Educational Research 61, no. 4: 407-50. 